\title{
The evolution of thick coal seams mining methods in China
}

\author{
Qiao Jianyong ${ }^{1,2}$, Wang Zhiqiang*1, Zhao Jingli ${ }^{1}$ \\ ${ }^{1}$ China University of Mining and Technology (Beijing) Ding No.11 Xueyuan Road, Haidian District, \\ Beijing China, 100083 \\ ${ }^{2}$ Beijing University of Posts and Telecommunications 10 Xitucheng Road, Beijing, China, 100876
}

\begin{abstract}
The article is shown that the main methods used in China for coal mining from thick seams at the moment are two methods - the Complex mechanized method of developing seams at their full capacity (used only in simple geological conditions and is an additional method for the following) and Complex mechanized mining method with coal production (which is used mainly, including in difficult conditions). Despite the fact that these methods have positively proven themselves over the years, their use has a number of significant drawbacks, including a low extraction rate, an increased risk of endogenous combustion and rock burst, and others. Currently, a promising way is a development method with a diagonal (cross-shaped) arrangement of drifts, which helps to eliminate many of the shortcomings of previous methods, including a low recovery coefficient, the risk of spontaneous combustion, the need to support the drift and others. It is expected that this method will be widely used for underground coal mining in deep mines in China with difficult mining and geological conditions.
\end{abstract}

\section{Introduction}

The overall balance of China's produced energy resources can be summarized as "Rich coal reserves, poor oil reserves, and rare natural gas". According to the state statistical service of China, in 2018, the gross consumption of coal in the country reached 4.64 billion tons, which accounted for $59 \%$ the total gross energy consumption, while the percentage of oil consumption was $18.9 \%$, and natural gas $-7.8 \%[1,2]$. Other energy sources accounted for $14.3 \%$, which were represented by electricity generation from hydro and nuclear power plants; alternative energy sources (wind power) and others, as shown in figure 1. Consequently, coal continues to occupy a leading position among energy sources in the country.

\footnotetext{
* Corresponding author: Wang Zhiqiang
} 


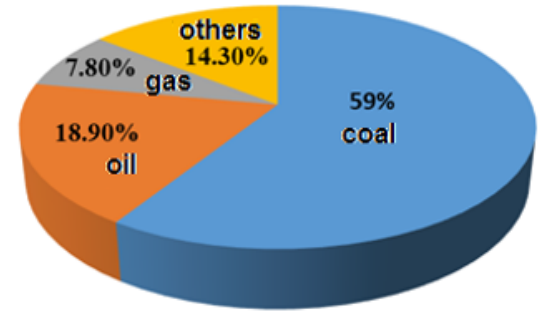

Fig.1. Percentage of energy consumption in China

Underground mining accounts for about $95 \%$ of all coal production in China. At the same time, $44 \%$ of coal is extracted from thick seams. Thus, the development of thick coal seams is of great importance for the Chinese economy. At the same time, when developing coal seams, a number of specific issues arise that require detailed consideration, including: the extraction coefficient, the risk of spontaneous combustion, ventilation, rockbursts, and others that are also typical for Russian conditions [3-9]. He Manchao, a member of the Chinese scientific academy, noted that the recovery rate when using the underground mining method in China is less than $50 \%$, so the annual material damage from coal losses is huge for the country and can be up to two trillion yuan. It should also be noted that the depth of development of mines located in the East of China is increasing by 15-25 meters per year and mining and geological conditions are becoming more difficult. For this reason, Chinese scientists are constantly engaged in research in the field of methods and technologies for developing thick coal seams [10-14].

The aim of this article is to review the development of technologies for developing thick coal seams and evaluate them. First, we will consider traditional methods of developing thick coal seams; evaluate their advantages and disadvantages, as well as the conditions for their application. Then a new method will be considered that can help in solving individual problems that arise during coal mining.

\section{Traditionally used methods for developing thick coal seams}

Currently, the method of layer development of thick seams is a thing of the past. But still widely used methods that were borrowed from foreign mining companies in the 80-ies of the last century. First of all, it is a complex mechanized method of production with the release of coal and a complex mechanized method of production at full capacity of the coal seam.

\subsection{Complex mechanized method of mining with the release of coal}

The method of developing thick seam with the release of sub-roof coal includes mechanized extraction of coal in the slash layer and the release of sub-roof coal to the rear conveyor in the working space of the treatment face. Initially, a combine harvester cuts the coal seam. This part of the coal gets to the front conveyor. The cut part of the coal from the upper pack is destroyed under the influence of rock pressure and released to the rear conveyor located behind the mechanized complex. This method of coal mining is used on thick coal seams with an angle of incidence from 0 to 45 degrees, as shown in figure 2 . This method was used, for example, when developing thick rockburst hazardous seam at the Huafeng mine [15]. This method widely used in Russia [16]. 


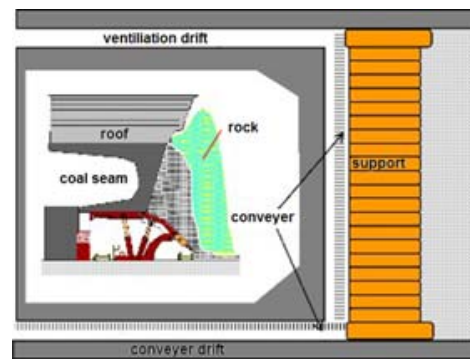

a) development technology

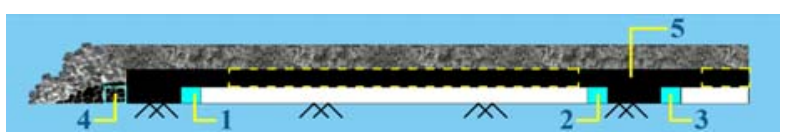

1,2 - ventilation gallery's; 3 - gallery of the next working face; 4 - gallery of the previous face in operation; 5 - coal pillar.

b) the location of gallery's

Fig. 2. Complex mechanized mining method with coal output

From figure 2, it is clear that the height of the mechanized complex is less than the capacity of the coal seam, and the roof coal, destroyed by natural rock pressure, is released to the rear conveyor, so the complex spends less energy on working off the formation. This method is characterized by high efficiency of processing and low energy consumption. With success, the complex mechanized method of mining with the release of coal has been used in China for about forty years; however, the disadvantages of the method have not been eliminated until now. These include:

1. Low extraction rate. This disadvantage is explained by the following. Mechanized complex does not contact the roof of the coal seam, thereby produced remain up to $7 \%$ $12 \%$ of stocks; at the beginning and end of the bottom part of the coal from the roof of the reservoir is left to protect the roadway, which in turn makes up 4\% of stocks in initial and final stages of seam development cannot produce coal, the loss in this account from $1.5 \%$ to $2.3 \%$; the loss in the entire range from $7 \%$ to $15 \%$. Due to these losses, the recovery rate does not reach $93 \%$, and the average is $75 \%$.

2. Methane explosion and fire hazard. In the developed space, spontaneous combustion can easily occur, which can be caused by abandoned coal.

3. Selecting the location and fixing the drift. Figure 2 shows that it is difficult to choose the appropriate location of the drift due to the significant effect of rock pressure, which is manifested under the influence of a large depth of development; it is very difficult to manage the roof when it is covered with thick and soft rock layers.

4. Stability of the equipment position. As shown in figure 3, hardware stability is calculated using formula 1:

$$
G(\sin \alpha-\cos \alpha \times f 2) \leq N(f 1+f 2)
$$

where: $G$ - weight support; $\alpha$ - the angle of incidence of the coal seam; $f 1, f 2-$ coefficients of friction lining with the roof and soil; $N$ is the reaction support.

A brief analysis of formula (1) shows that the stabilization is negatively affected by a decrease in the height of the support when it is detached from the roof of the face. In other words, at the moment of moving the support forward, when the workload is reduced $(N=0)$, the stabilization of the support rack is violated, as evidenced by practice. Usually, if the face is waterlogged, the equipment slides on the face soil at a reservoir drop angle of more than 12 degrees. In this regard, it is necessary to perform additional measures to prevent the equipment from sliding and falling in a bottom hole with a reservoir drop angle of more than 18 degrees. In China, the difficult conditions for the development of thick coal seams are due to their angles of incidence of more than 30 degrees, so it is necessary to break the coal seam into several layers to reduce the angle of inclination for the treatment of each layer. 


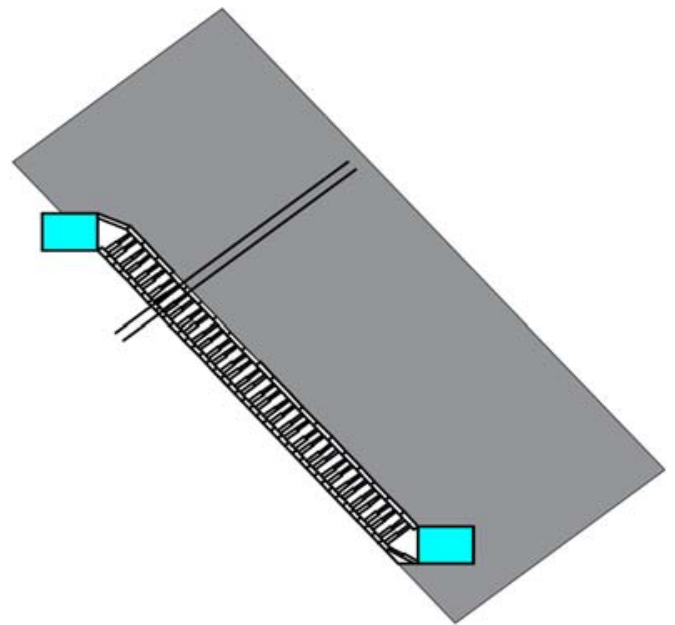

Fig. 3. Stabilization of equipment in a thick coal bed with a large angle of incidence

\subsection{Complex mechanized method for developing thick coal seams at full capacity}

In China, over 30 years of using and upgrading this method, certain successes have been achieved, for example: a world record for the amount of coal produced per day, increased production efficiency, increasing the height of the mechanized face of the combine and the development of reservoirs with a capacity of up to 8.8 meters.

In the Shanwan mine, Fig. 4, the face height is 8.8 meters, the length of the lava is 300 meters, and the size of the excavation area along the stretch is $5.27 \mathrm{~km}$. By the end of 2019 , about $1.22 \mathrm{~km}$ of this section has already been worked and 4.41 million tons of coal has been extracted. The highest daily production rate exceeded 60 thousand tons, which is currently the world record for daily coal production at the mine.

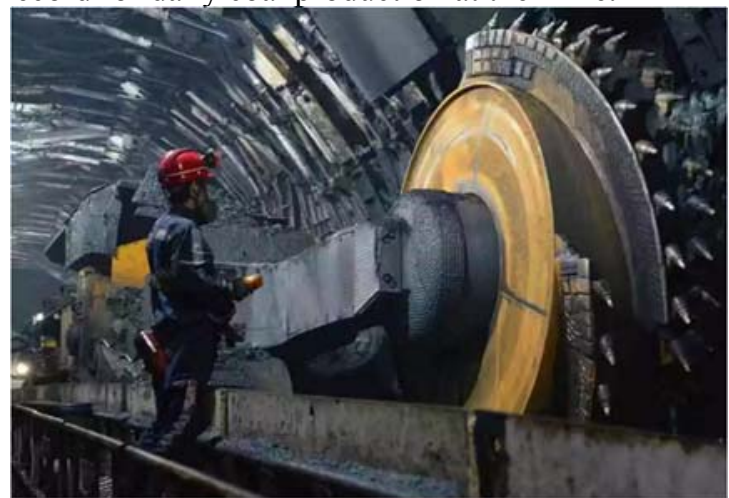

Fig. 4. Complex mechanized method for developing coal seams at full capacity

However, this method also has disadvantages, the main of which are the following:

1. Low extraction rate. Often the thickness of the coal seam is greater than the maximum possible face height, and the thickness of the formation varies along the strike. Therefore, it is impossible to avoid the loss of coal in the soil and the roof of the formation. In addition, with a large depth of development, you need to leave a wider coal target to protect the neighboring drift from high rock pressure. These losses reduce the recovery rate.

2. Problems with the stability of the equipment. Since equipment of large dimensions is used, it is likely to slip on the bottom soil, as well as fall. In addition, massive hydraulic 
supports can fall into the bottom of the face. All this negatively affects production processes.

3. Coal flaking in the face. At a high height of the exposed coal face, the probability of coal flaking and shedding increases, which can lead to equipment blockage and roof collapse.

The method has advantages under the following conditions:

1. Simple geological conditions, simple tectonic structure without folds and discontinuities. Only in this case it is possible to comply with the basic requirement for the safe and efficient development of the seam of great thickness.

2. Stable roof and bottom soil, strong enough coal. Otherwise, as long to develop high altitude slaughtering is without the lining, there is a flaking of the coal and the rubble of the roof. Also, if heavy equipment is located on relatively soft ground of the face, it easily falls into it.

3. The working angle should not exceed 12 degrees. Otherwise, there is a high risk of accidents with equipment sliding on the reservoir soil and falling.

\section{The improvement of methods of development of thick coal seams}

The main reason for the low coal recovery rate and increased risk of rockbursts in the complex mechanized method of extraction with release is the abandonment of a large coal pillar, whose width on average is from 20 to 30 meters, and sometimes reaches up to 80 meters.

The efforts of researchers and technical staff in the design departments of coal companies are aimed at eliminating these shortcomings, as well as improving the stability of mine workings. Improved development methods are briefly discussed below.

\subsection{Conducting coal face operations in cutting with roof stone layer to the goaf}

This method is shown schematically in Fig. 5 here you can see that the neighboring drift for mining is located in zone III, closer to zone IV, which is why the width of the coal pillar is large, and the drift in zone II falls into the reference pressure zone. The loss of coal for this variant of the drift arrangement is large, and the maintenance of the goaf is difficult.

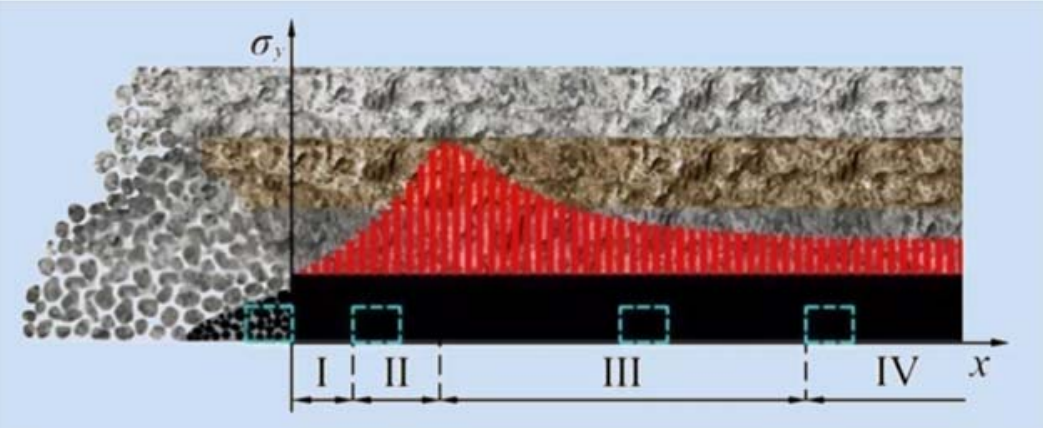

Fig. 5. Zonal distribution of reference pressure in the coal seam near the bottom I-zone of unstable pressed coal; II - zone of plastic deformations; III-elastic zone of increased reference pressure and elastic deformations; IV - zone of stress state of untouched massif 
To eliminate these disadvantages, the drift is located in zone II, in which it is separated from the goaf of previously spent lava only by zone I. This allows you to increase the extraction rate and is useful for maintaining the drift, over which the rock pressure is relatively lower.

As a rule, it is only possible to carry out a drift in cutting with roof stone layer after a moving cleaning face in the zone of steady rock pressure. To ensure the necessary step of lagging the bottom of the drift from the bottom of the lava, a step-by-step arrangement of the dredging sections is formed, as shown in Fig.6. The disadvantage of this method in the development of thick seams is that the drift is constantly located in the zone of intense plastic deformations and unstable host rocks, which greatly affects the rate of sinking of the development.

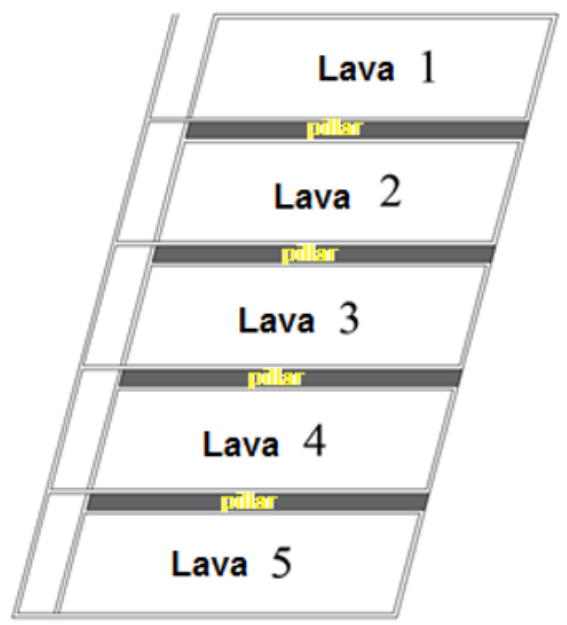

Fig. 6. Location of panel mine section in the development with the passage of drifts in cutting with roof stone layer to the goaf

In addition, it is difficult to correctly design the width of the whole, which is necessary to protect it from the effects of high mountain pressure. To use this method in China influenced the development of the adjacent stope has been repeatedly noted significant deformation and destruction of drift it is carried out in cutting with roof stone layer to the goaf.

\subsection{Location of the ventilation drifts close to the goaf}

The location of the ventilation drift close to the worked-out space of the previous lava makes it possible to further increase the recovery coefficient in comparison with the above method, as shown in Fig.7. 


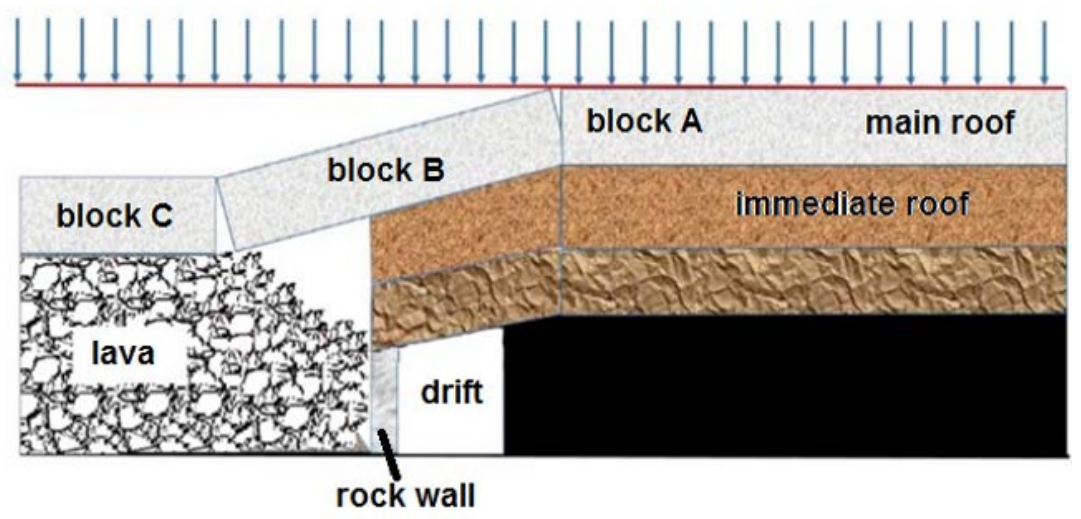

Fig. 7. Carrying out drift closes to the goaf

Following the progress of the face along the worked area, a support wall is laid out (Fig. 7), which later serves to protect the new ventilation drift. When using this method, a nonpillar mining operation is implemented with a high coefficient of coal recovery and a reduction in the risk of endogenous fires and rockbursts.

In 2000, this method was successfully tested at the Schiechiao mine, which previously used a complex mechanized method of mining with the release of coal. Subsequently, this method was also used in the mines of Yanchuan, Luan and others. However, this technology has not been widely adopted due to a number of shortcomings, the main of which are related to the need to lay out the support wall, which reduces the rate of development and is often not economically profitable. In Chinese, this situation is called "technology is viable, but the economy is not useful".

\subsection{The development method with diagonal location of drifts}

In 1998, a patent was obtained in China $[10,11]$ for a new method for developing thick seams. The purpose of this development was to solve the problems of increasing the coal recovery rate, supporting drifts, and stabilizing mining equipment in the treatment face. The method is called "the method of development with a diagonal (cross) arrangement of drifts", Fig. 8.

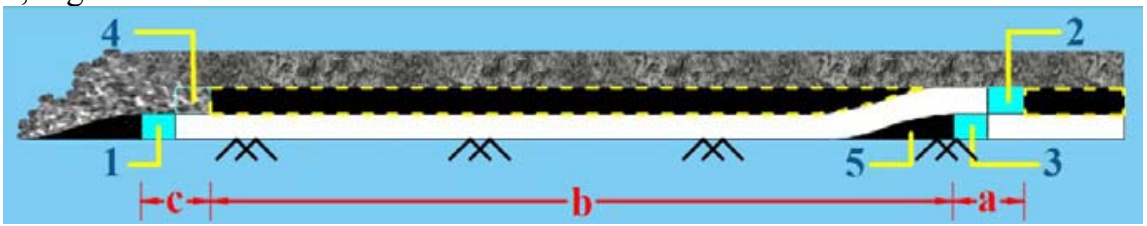

Fig. 8. Development method with a cross-shaped arrangement of drifts

1- ventilation drift (fresh stream); 2 - ventilation drift (outgoing jet); 3 - ventilation drift of the next face; 4 - drift of the previous face; 5 - loss of coal

As shown in Fig. 8, compared to other methods, here the drifts are located on two levels. The drift through which the outgoing jet leaves is located under the direct roof, and the ventilation drift with a fresh stream is located on the soil of the formation. The drifts are arranged diagonally (crosswise). This arrangement of drifts provides the following advantages:

1. Higher extraction rate. As shown in Fig. 9, no coal pillar is left over drifts 2 and 4, which increases the coal recovery rate by about $2 \%$. There is also no need to leave the pillar over drifts 1 and 3, which leads to an increase in the recovery rate by $4 \%$. In addition, there is no pillar between neighboring lavas, which can give an increase in the recovery rate by another $7 \%-15 \%$. 
Practice shows that in general, when switching to this method of development, the increase in the recovery rate were more than $10 \%$ for Chinese coal mines.

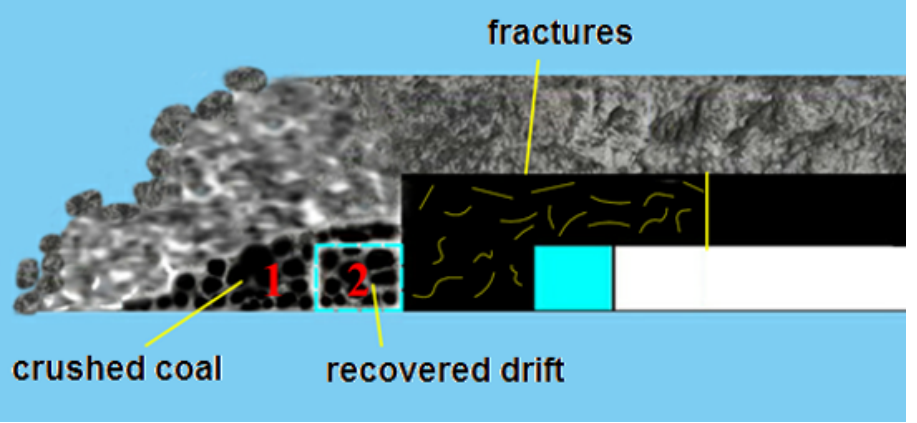

Fig. 9. Sources of coal losses in traditional and new mining methods

2. Reducing the risk of spontaneous combustion. It is obvious that when the coal recovery rate increases, the risk of spontaneous combustion is reduced due to the fact that less coal remains in the subsurface. The zones that leave less coal in the subsurface are listed above.

3. Increasing the stability of drifts. Drifts 2 and 4 (Fig. 8) are passed under the immediate roof of the formation, the rocks of which are stronger than coal. Drift 1 is located under the goal of the previous face in the discharge zone, which also contributes to its maintenance.

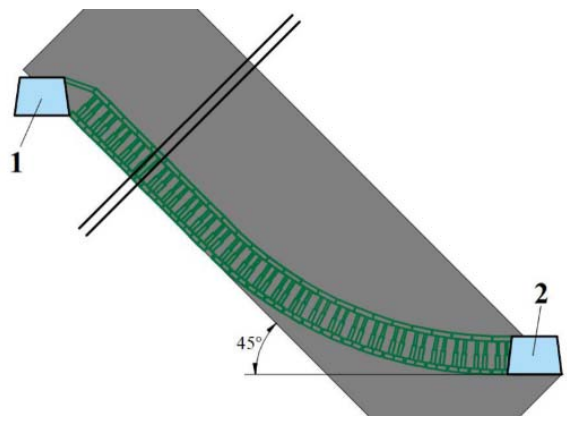

Fig. 10. Changing the face slope during the development of inclined thick seam

4. Increasing the stability of support posts and other mining equipment in the development of an inclined thick coal seam. As shown in Fig.10, drift 2 is located under the roof of the coal seam, and drift 1 is located on its soil. As a result, the overall slope of the face is reduced and sometimes even can be zero, which increases the stability of mining equipment. When the angle of inclination decreases $\alpha$, the formula (1) is transformed into the formula (2):

$$
\Sigma \mathrm{G}\left(\sin \alpha_{\mathrm{i}}-\cos \alpha_{\mathrm{i}} \times \mathrm{f} 2\right) \leq \mathrm{nN}(\mathrm{f} 1+\mathrm{f} 2), \mathrm{i}=1 \ldots \ldots n
$$

where $n$ is the number of support posts.

From the comparison of formulas (1) and (2), it can be seen that in the second case, the condition will be fulfilled more easily due to the presence of terms with a low value of the angle $\alpha$.

The described method was developed more than 20 years ago and has a great prospect of wide application. Fig. 11 shows the scheme of rock movement and formation of shift trough. It can be seen that due to the lack of a pillar, the movement is smoother and safer for natural and engineering objects on the surface [12]. This feature affects other geomechanical processes during development, including the risk of gas-dynamic and dynamic phenomena. It is known that to reduce the risk of rockbursts, non-pillar development systems are recommended [17-21]. 


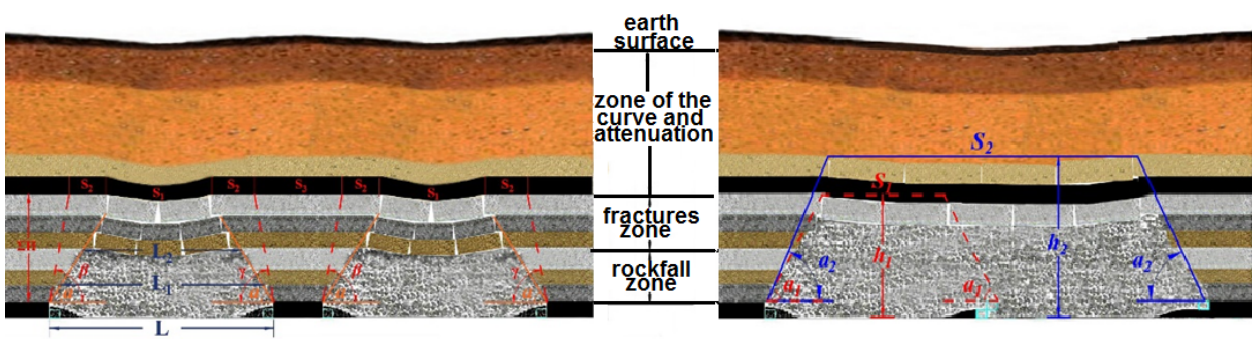

a) pillar between neighboring laves

b) non-pillar working out

Fig. 11. The nature of displacement in different ways of developing a thick seam

Figure 12 shows the pressure distribution near the faces. When the drift is located under the collapse zone, it is located in the unloaded zone, where the pressure is lower than gravity and does not depend on the depth of the development. This location of workings are called the "negative pillar".

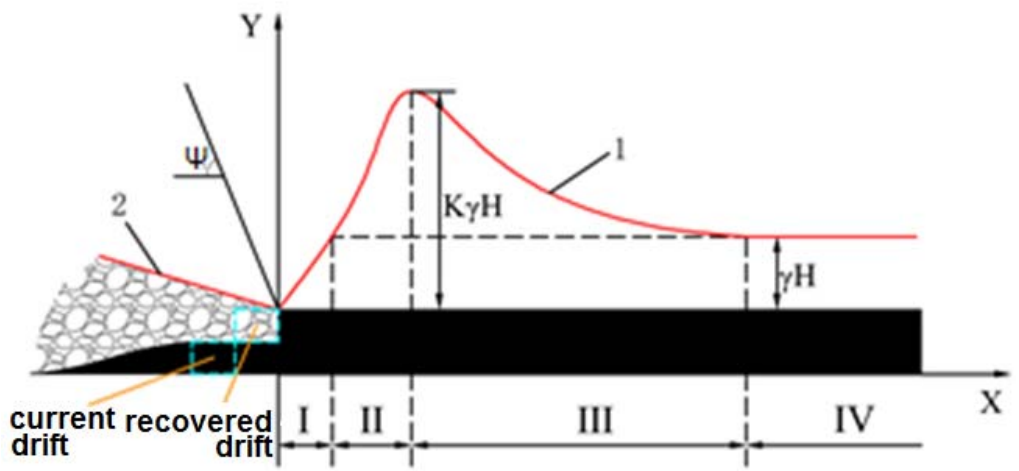

Fig. 12. Location of the drift in the discharge zone, "negative pillar".

1,2 - rock pressure above the coal seam (1) and in the zone of full displacement (2); $\Psi$ - angle of full displacement

The location of drifts in the discharge zone is of great importance for their maintenance at great depths and is relevant for the Eastern regions of China, where there are many mines that develop rockburst hazardous seams. This method with a diagonal arrangement of drifts is already used in eight large mining enterprises in China, where its economic and social effect is noted.

\section{Conclusions}

In this paper, modern methods of coal mining used in China are considered. The analysis allows us to draw the following conclusions:

1. The main methods used in China for extracting coal from thick seams at the moment are two methods - the complex mechanized method of developing reservoirs at their full thickness (used only in simple geological conditions and is an additional method for the following) and the complex mechanized method of mining with the release of coal (which is used mainly, including in complex conditions). Despite the fact that these methods have proven themselves over the years, their use has a number of significant disadvantages, including a low recovery rate, the need to locate and support the drift, the risk of spontaneous combustion, and others.

2. To solve the problems of low recovery rate and the need to support the drift, Chinese scientists are constantly conducting research, thanks to which it was possible to develop a successful solution in which the ventilation drift is carried out in cutting with roof stone 
layer to the goaf. At the same time, further research is needed for large-scale application of this solution.

3. A promising method of development with a diagonal (cross-shaped) arrangement of drifts, which helps to eliminate many disadvantages of previous methods, including a low recovery rate, the risk of spontaneous combustion, the need to support the drift, and others. It is expected that this method will be widely used for underground coal mining in deep mines in China with complex mining and geological conditions.

\section{References}

1. 2018 Statistical bulletin on national economic and social development of China[J] // China Statistics, 3, 8-22 (2019)

2. China Mineral Resources[R]. Beijing: Geological Publishing House, 09, 16-19 (2019)

3. N. O. Kaledina, S. S. Kobylkin, A. S. Kobylkin, Eurasian Mining, 1, 41-44 (2016) DOI:10.17580/em.2016.01.07.

4. S. V. Slastunov, K. S. Kolikov, G. P. Ermak, \& E. P. Yutyaev, Gornyi Zhurnal, 4, 46-49 (2015) DOI:10.17580/gzh.2015.04.08.

5. A.S. Batugin, Rock Mechanics for Natural Resources and Infrastructure DevelopmentFontoura Rossa and Pavon Mendoza (Edd), 1261-1268 (IRSM-2020, Brasil). ISBN 978-0367-42284-4

6. S. V. Balovtsev, Mining Informational and Analytical Bulletin, 6, 173-183 (2019) DOI:10.25018/0236-1493-2019-06-0-173-183. [In Russian].

7. V. A. Malashkina, Mining Informational and Analytical Bulletin, 9, 131-137 (2019)

8. M. V. Pavlenko, O. V. Skopintseva, Mining Informational and Analytical Bulletin, 3, 4350 (2019) DOI:10.25018/0236-1493-2019-03-0-43-50.

9. S. V. Slastunov, K. S. Kolikov, A. A. Zakharova \& E. V. Mazanik, Solid Fuel Chemistry, 49(6), 381-386 (2015) DOI:10.3103/S0361521915060117.

10. Zhao Jingli, Wu Jian. Full-seam mining adopted roadway layout of stagger arrangement in thick coal seam [P]. China patent: ZL98100544.6, 2002-01-23

11. Zhao Jingli, Li Bao, Journal of Liaoning Technical University (Natural Science), 17(3), 237-239 (1998)

12. Wang Zhiqiang, Zhao Jingli, Zhang Baoyou, etc. Journal of China Coal Society, 33(9), 961-965 (2008)

13. M. He, H. Xia, X. Ji, W. Gong, F. Zhao, K. Liang, Journal of Rock Mechanics and Geotechnical Engineering, 4(2), 97-114 (2012)

14. Zhao Jingli, Fu Qiang, Paper presented at the Mining Science and Technology '99, 3942 (1999)

15. Qiao Jianyong, A. S. Batugin, I. M. Batugina, Yu Lijiang, Zhao Jingli, The Conditions of Geodynamic Phenomena at Huafeng Mine in China (Moscow: Sputnik+, 2016)

16. V. I. Klishin, Mining Informational and Analytical Bulletin, Special issue 48, 52-63 (2018)

17. I. M. Petukhov, Proc.6th Congress International Society for Rock Mechanics, Montreal, 2, 1207-1210 (1987)

18. Zhang Junwen, Liu Chang, Li Yulin, et al., Journal of China Coal Society, 43(8), 2133$2143(2018)$

19. Cheng Yunhai, Ma Yankun, Hu Zhaofeng, et al., Journal of China Coal Society, 41(3), 564-570 (2016)

20. Li Zhenlei, Dou Linming, Cai Wu, et al., Rock Mechanics and Rock Engineering, 49(2), 621-629 (2016)

21. O. I. Kazanin, M. G. Mustafin, A. A. Meshkov, \& A. A. Sidorenko, Naukovyi Visnyk Natsionalnoho Hirnychoho Universytetu, 2, 51-56 (2015) 